\title{
A Simulation Based Geometrical Analysis of MEMS Capacitive Pressure Sensors for High Absolute Pressure Measurement
}

\author{
Ahmed Gafar*, Galal Atlam*, and Imbaby I. Mahmoud** \\ * Faculty of Elect., Eng., Minufiya University, EGYPT. \\ ** Atomic Energy Authority, EGYPT.
}

(Received: 01-April-2015 - Accepted: 03-May-2015)

\begin{abstract}
This paper presents the performance characteristics evaluation of MEMS capacitive pressure sensor. This type of absolute pressure measuring sensor is used for pulse rate measurement. Polysilicon material provides a higher sensitivity when chosen as diaphragm material. Two MEMS capacitive pressure sensors with varying geometries are analyzed in Matlab simulation software. The geometries are very common having parallel plates with spring loaded. In first stage the shape of the parallel plates is circular and in second case of the parallel plate is square. During modeling of these two diffident shaped sensors, the area of parallel plates in both cases is considered as equal. Once the geometries are formed, the electromechanical analyses have been performed. It is observed that these types of pressure sensors can withstand a wide range of absolute pressure from kilo Pascals to several order of mega Pascals. In this work, Matlab environment is employed to model this sensor and accurate model is devised to study its performance. Simulation results are obtained and compared with published work of FEM (Finite Element Method) based Multiphysics simulation platform and full argument is obtained. The proposed model allows handling different parameters affecting the performance of this sensor.
\end{abstract}




\section{Introduction}

The microfabricated pressure sensor is one of MEMS devices used in a wide range of applications. In MEMS technology, piezoresistive pressure sensors are very common. However, in the past years capacitive pressure sensors have received attention due to several advantages in comparison to piezoresistive pressure sensors. The main disadvantage of the piezoresistive pressure sensor is the inherent temperature dependence of piezoresistive coefficients [1]. Moreover, capacitive pressure sensor has lower power consumption than piezoresistive pressure sensor [2]. But piezoresistive pressure sensor most widely used than capacitive pressure sensor because of two reasons; capacitive structure is more complicated to fabricate and the capacitive sensing principle is sensitive to parasitic capacitances. The structure of the capacitive pressure sensor is more complicated, because it involves formation of a cavity that separates the two sensing electrodes from each other. Formation of such a cavity is done in two different ways. For first case multiple film depositions and etch of a buried sacrificial layer [3-6] or in second case bonding after the cavity has been etched into one of the wafer. Wafer bonding is done by fusion bonding of two silicon wafers or anodic bonding of a silicon wafer and a glass wafer [7-9]. Capacitive pressure sensors are required in applications including bio-medical systems, environmental monitoring and industrial process control. Capacitive pressure sensors provide low noise, high sensitivity, have low temperature sensitivity and are preferred in many emerging high performance applications and can withstand a lot of vibration. Micromachined capacitive pressure sensors have typically used an elastic diaphragm with springs and a sealed cavity in between the diaphragm and the substrate below. There is a pair of parallel plate which forms capacitor. Lower plate is fixed and upper plate acts as movable plate which is attach with spring and four boundaries are fixed. Pressure is applied on upper plate; it deforms which changes the distance between two plates due to this capacitance changes. The change of capacitance is used for measuring pressure [10, 11].The design parameters of MEMS based diaphragm type capacitive pressure sensors using Matlab software is explored. Two different shaped diaphragms with the same area for sensing high absolute pressure are designed. 
Mechanical, electromechanical as well as material studies are performed. The analyzed results are in the form of 2-D plots. The outcome of these designed sensors are discussed and compared against their efficiencies.

\section{Methods and materials}

\section{A. Mathematical modeling:}

The maximum stress for circular diaphragm is given by [12]:

$$
\sigma_{\max }=\frac{3 \gamma w}{8 \pi h^{2}}
$$

The maximum deflection of the circular plate occurs at the centre position of the plate is given by [13]:

$$
W_{\max }=\frac{3 w\left(m^{2}-1\right) a^{2}}{16 \pi E m^{2} h^{3}}
$$

The maximum stress at the middle of each edge for square diaphragm is given by [12]:

$$
\sigma_{\max }=\frac{0.309 P a^{2}}{h^{2}}
$$

The maximum deflection for square diaphragm is given by [14]:

$$
W_{\max }=\frac{0.0138 P a^{4}}{E h^{3}}
$$

Where:

$W:$ is the total force acting on the plate, 

$h:$ is the diaphragm thickness,
$a$ : is the radius of the diaphragm,
$P:$ is the pressure difference across the diaphragm,
$E$ : is the Young's modulus of the diaphragm material,
$\gamma:$ is the Poission's ratio of the diaphragm material,
$m$ : is the reciprocal of the Poisson's ratio

Eq. 1, Eq.2, Eq. 3 and Eq. 4 are describing for performing the analytical analysis of the proposed MEMS based capacitive pressure sensor. The capacitance between two parallel electric conductive plates is given by [15-16]:

$$
C=\varepsilon_{0} \varepsilon_{r} \frac{A}{d}
$$

Where:

$C$ : is capacitance,

$\varepsilon_{0}$ : is dielectric constant of vacuum,

$\varepsilon_{r}$ : is the dielectric constant of material,

$A$ : is area of electrode plate,

$d$ : is the gap between two electrode plate.

The relationship between the capacitance change and the applied pressure for circular and square diaphragms is defined as sensitivity and is given by [17-21]:

$$
S=\frac{\Delta C}{P}=\frac{3\left(1-\gamma^{2}\right) R^{4} \varepsilon_{0} \varepsilon_{r} A_{\text {sense }}}{16 E h^{3} g^{2}}
$$

Where:

$S:$ is the sensitivity,

$\Delta C$ : is the change in capacitance,

$P:$ is the pressure difference across the diaphragm,

$R$ " is the radius of the diaphragm, 
$h:$ is the thickness of the diaphragm

$E$ : is the Young's modulus of the diaphragm material,

$\gamma:$ is the Poission's ratio of the diaphragm material,

$A_{\text {sense }}$ "is the area of the moving plate

$g:$ is the sensing gap between the moving plate and the fixed plate

\section{B. Matlab modeling}

Matlab software is used to predict mechanical response to a load, such as force or moment applied to a part of the constructed model. This part is to be simulated is broken down into small discrete element - this procedure is called meshing. Each element has a no. of nodes and its corners at which it interacts with neighboring element. Thus the system Partial Differential Equation (PDEs) is assumed to be linear element within the nodes and is solved in matlab modeling.

\section{Sensor layout}

For design purpose, the two different geometries (circular and square) of the diaphragm are designed in such a way that their area between the plates is made similar. Both cases there are two plates. Lower one is fixed and upper one is movable. Pressure is applied on upper plate. Distance between two plates changes when pressure is applied and due to these capacitance changes. The dimensions of both the square and circular shaped capacitive pressure sensor is provided below as shown in Fig. 1

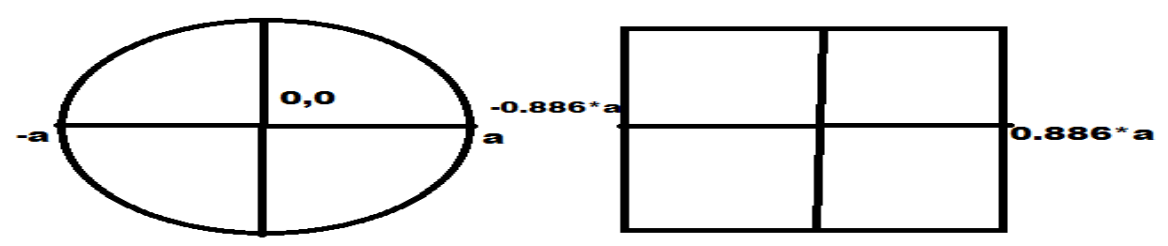



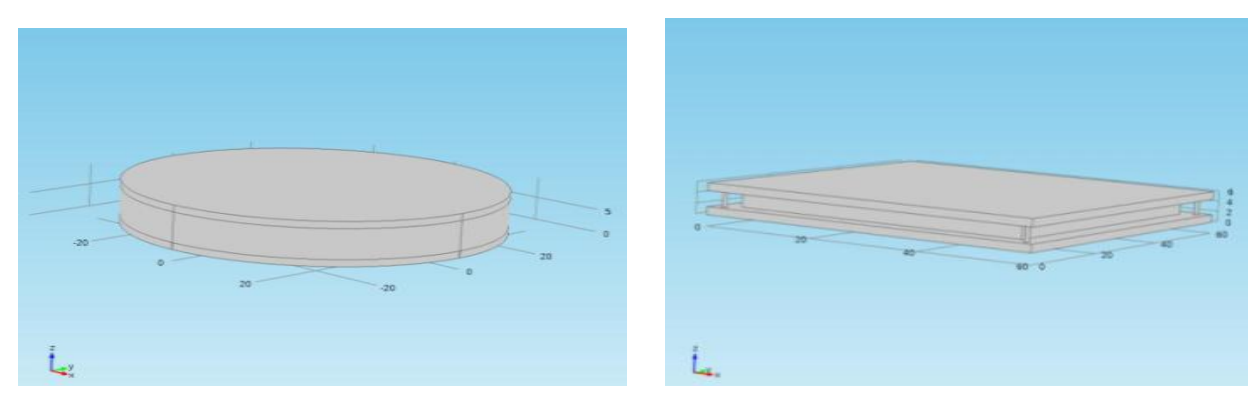

Fig. 1: Cross-section and 3D view of the sensor geometries

Table 1: Parameters used in MEMS capacitive pressure sensor

\begin{tabular}{|l|l|}
\hline Side length of square diaphragm $[\mu \mathrm{m}]$ & 60 \\
\hline Radius of circular diaphragm $[\mu \mathrm{m}]$ & 33.84 \\
\hline Thickness of diaphragm $[\mu \mathrm{m}]$ & 1.5 \\
\hline Separation gap between the plates $[\mu \mathrm{m}]$ & 3.0 \\
\hline
\end{tabular}

\section{Material Analysis}

The physical properties of Polysilicon are recorded in table 2. These properties are used in performing the analysis of the two designed MEMS based capacitive pressure sensor model in Matlab software.

Table 2: Properties of Polysilicon material

\begin{tabular}{|l|l|}
\hline Young's modulus $[\mathrm{pa}]$ & $160 \times 10^{9}$ \\
\hline Poisson's ratio & 0.22 \\
\hline Density $\left[\mathrm{kg} / \mathrm{m}^{3}\right]$ & 2320 \\
\hline Thermal expansion coefficient $\left[\mathrm{K}^{-1}\right]$ & $2.6 \times 10^{-6}$ \\
\hline Thermal conductivity $[\mathrm{W} / \mathrm{m} * K]$ & 34 \\
\hline Relative permittivity & 4.5 \\
\hline
\end{tabular}




\section{Results and discussion}

A wide range of mechanical, electromechanical and polysilicon material studies of the proposed two geometrical structures have been performed in the Matlab Software. In this paper, effect of various parameters for designing sensor is analyzed and discussed below.

\section{A. Design sensor layout}

Two types of geometrics are designed. Sensor layouts are given on Fig.2 and Fig.3. Deflection is maximum at center of the diaphragm and minimum at side of the diaphragm.
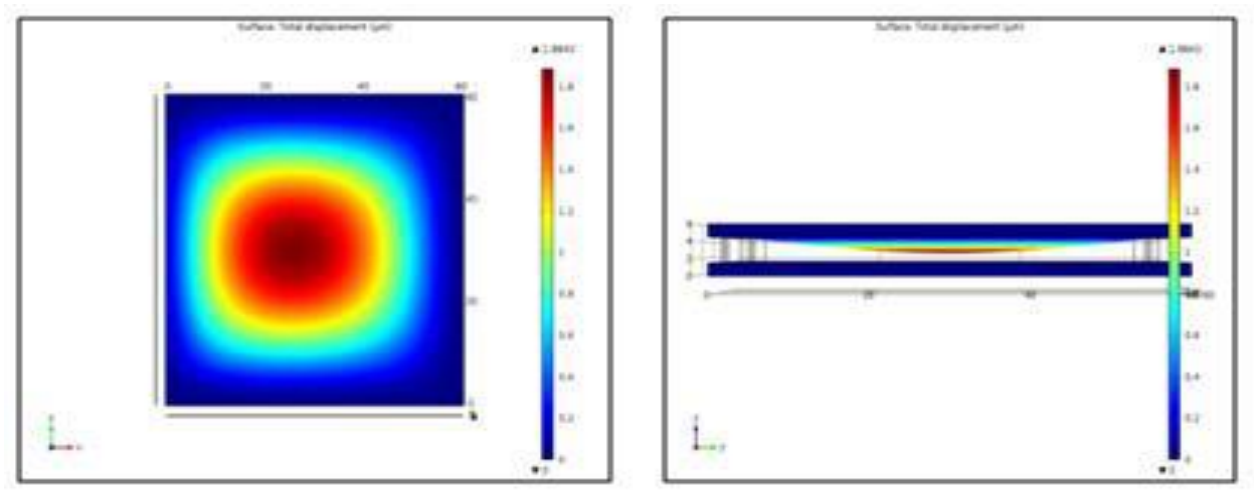

Fig.2: Square sensor layout (a) top view (b) side view

Applied pressure vs. deflection is measured and change in capacitance is measured. In Fig. 2(a, b) and 3(a, b) red colure shows maximum deflection at center of the diaphragm and blue colure shows minimum deflection at side of the diaphragm.

\section{B. Effect of Distance between two Diaphragms}

Distance between two diaphragms is very important parameter for designing diaphragm type capacitive pressure sensor. If the distance 
between two plates increases, the capacitance decreases. In Fig.4, the change in capacitance due to varying distance between two diaphragms is plotted. These studies we have done only with square shaped diaphragm as the area of two geometrical shapes diaphragms is considered as equal.

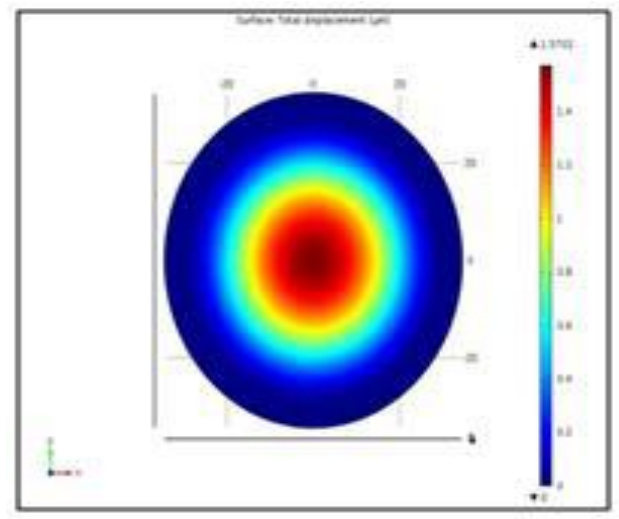

(a)

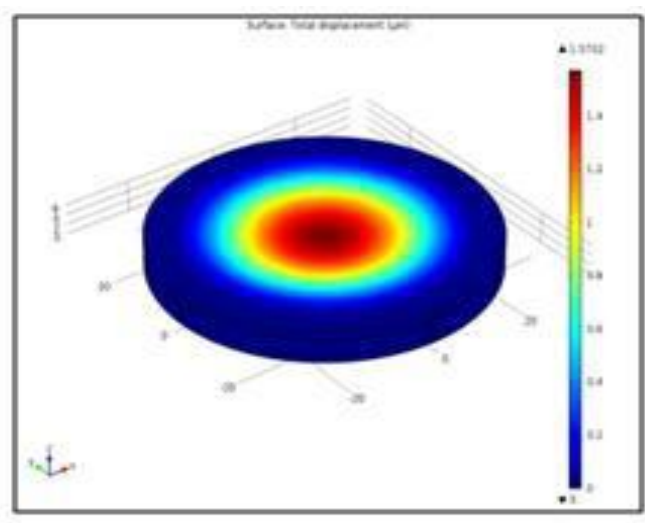

(b)

Fig.3: Circular sensor layout (a) top view (b) side view

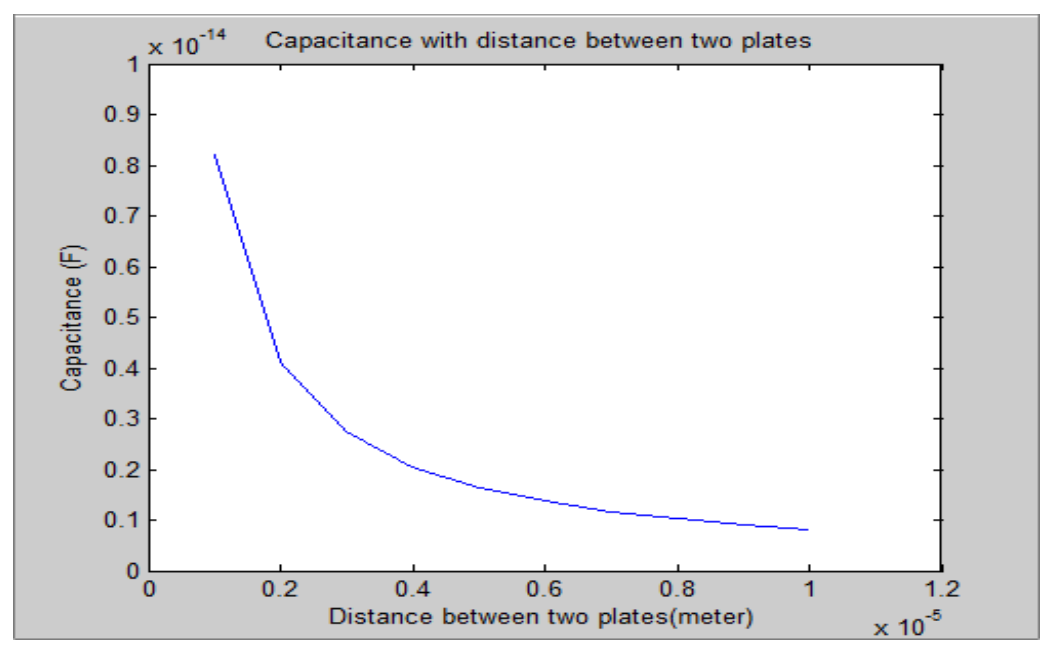

Fig. 4: Plot of capacitance with the variation of the distance between the plates 


\section{Effect of thickness of diaphragm on sensor performance}

\section{1- Deflection}

Thickness is very important parameter for diaphragm deflection. If diaphragm thickness is increased, deflection decreases. Diaphragm deflection is inversely proportional to diaphragm thickness as shown in Fig.5 (a) circular diaphragm and Fig.5 (b) square diaphragm, which show how the deflection for different diaphragm thickness varying with applied pressure. For different diaphragm thickness, deflection in circular shaped diaphragm is higher than in square shaped diaphragm. FEM and MATLAB results [12] showed that the deflection increased with applied pressure as theoretically predicted in Eq. (2) and Eq. (4) as shown in Fig. $5(\mathrm{a})$.

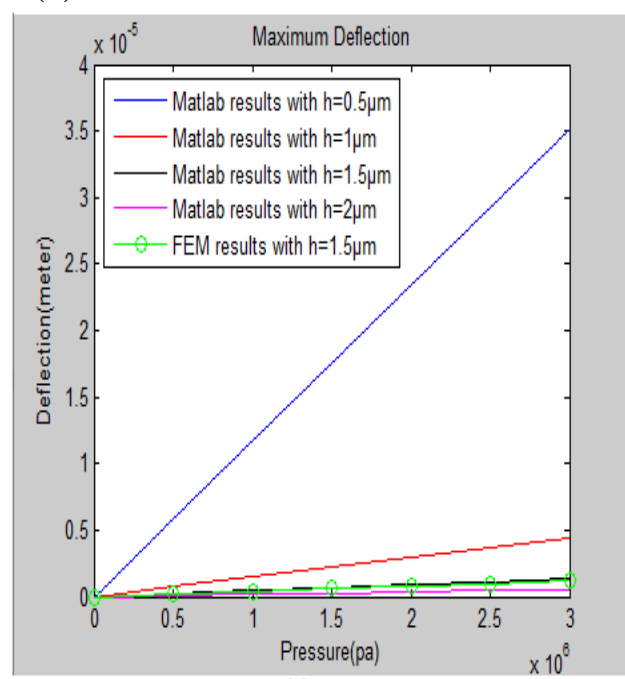

(a)

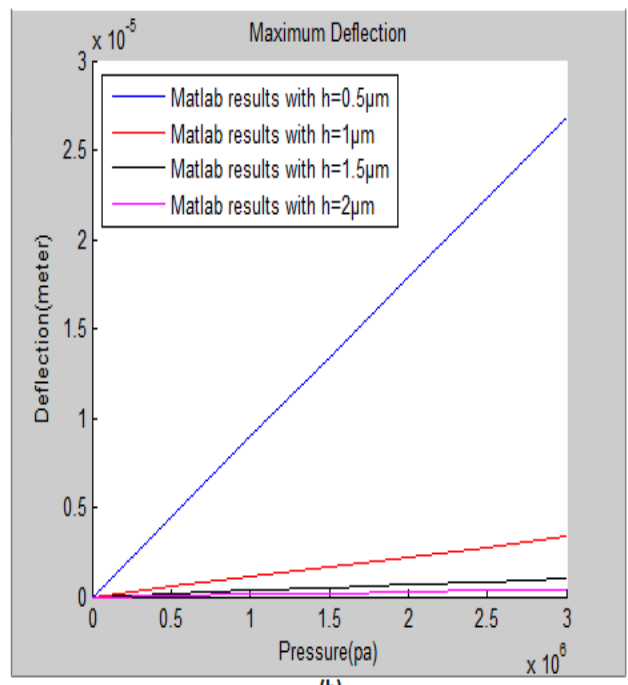

(b)

Fig.5: Plot of the deflection with diaphragm thickness, with the range of applied pressure from (0-3) MPa (a) For circular shaped diaphragm, (b) For square shaped diaphragm.

\section{2- Stress}

If diaphragm thickness is increased, stress decreases. Diaphragm stress is inversely proportional to diaphragm thickness as shown in Fig.6 (a) 
circular diaphragm and Fig.6 (b) square diaphragm, which show how the stress for different diaphragm thickness varying with applied pressure. If diaphragm thickness increases then pressure withstand capability also increases. For different diaphragm thickness, stress in square shaped diaphragm is much higher than in circular shaped diaphragm.

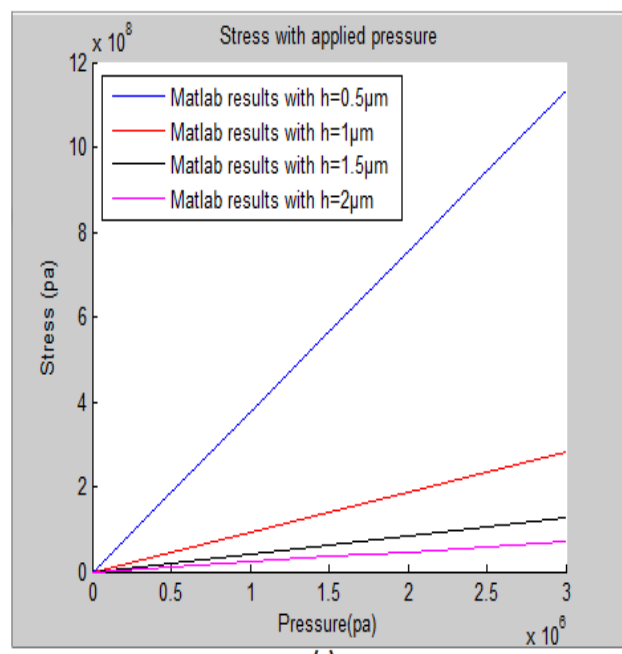

(a)

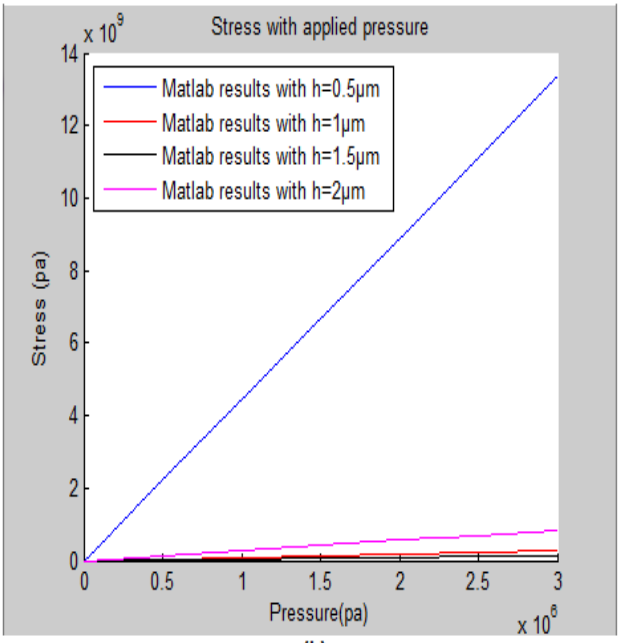

(b)

Fig.6: Plot of the stress through different diaphragm thickness with the range of applied pressure from (0-3) MPa (a) For circular shaped diaphragm, (b) For square shaped diaphragm.

\section{3- Change in capacitance}

Change in capacitance is measured with respect to applied pressure is shown in Fig.7 (a) circular diaphragm and Fig.7 (b) square diaphragm; it is observed that applied pressure vs. change in capacitance is maximum for thin diaphragm. As a result, low thickness diaphragm is more sensitive than high thickness diaphragm. For different diaphragm thickness, change in capacitance in circular shaped diaphragm is much higher than in square shaped diaphragm. FEM and MATLAB results [12] showed that the change in capacitance increased with applied pressure as shown in Fig. 7(a and $b)$. 

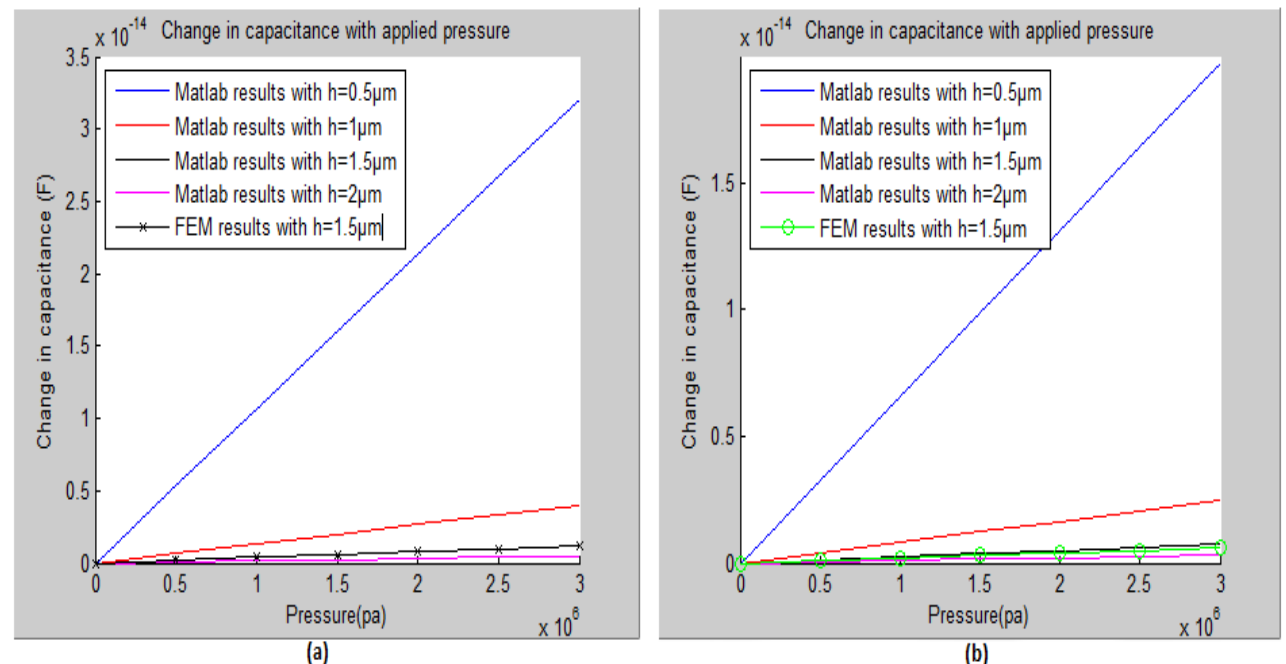

Fig.7: Plot of change in capacitance through different diaphragm thickness with the range of applied pressure from (0-3) MPa (a) For circular shaped diaphragm, (b) For square shaped diaphragm.

\section{4- Sensitivity}

If diaphragm thickness is increased, sensitivity decreases. Diaphragm sensitivity is inversely proportional to diaphragm thickness as shown in Fig.8 (a) circular diaphragm and Fig.8 (b) square diaphragm, which show how the sensitivity for different diaphragm thickness varying with applied pressure. If diaphragm thickness increases then pressure withstand capability also increases. For different diaphragm thickness, sensitivity in circular shaped diaphragm is much higher than in square shaped diaphragm.

\section{D- Effect of applied pressure on sensor performance}

\section{1- Deflection}

If applied pressure is increased, deflection increases as shown in Fig.9 (a) circular diaphragm and Fig.9 (b) square diaphragm, which show how the 
deflection for different applied pressure varying with diaphragm thickness. For different applied pressure, deflection in circular shaped diaphragm is higher than in square shaped diaphragm.

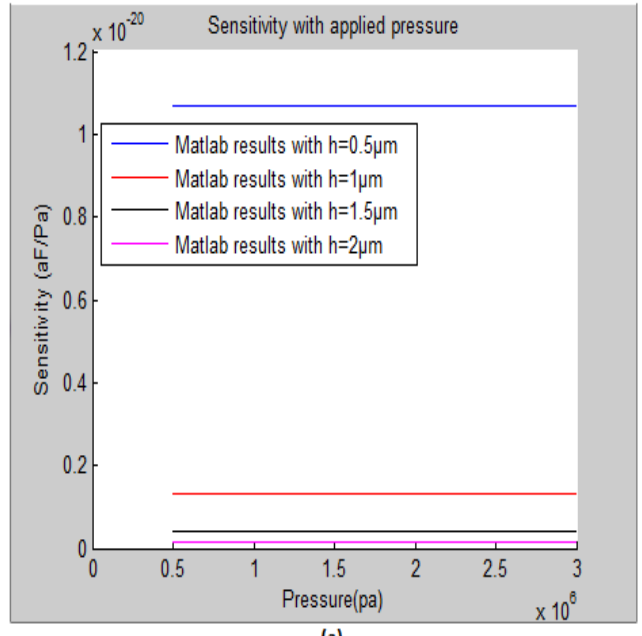

(a)

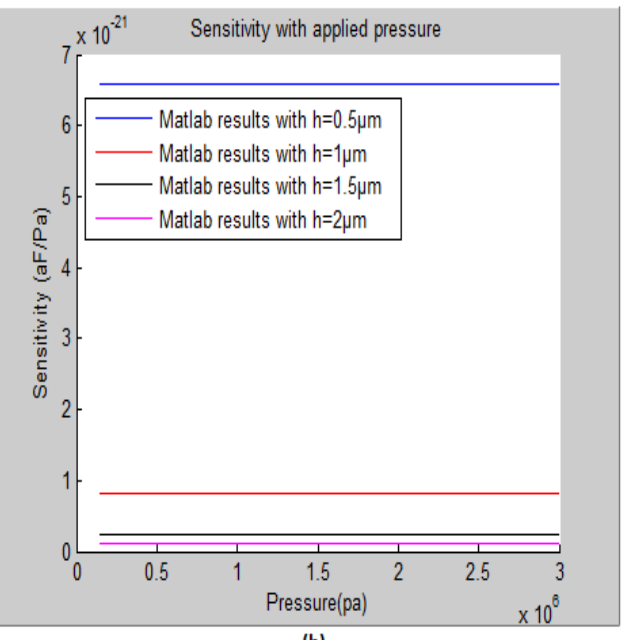

(b)

Fig.8: Plot of sensitivity through different diaphragm thickness with the range of applied pressure from (0-3) MPa (a) For circular shaped diaphragm, (b) For square shaped diaphragm.
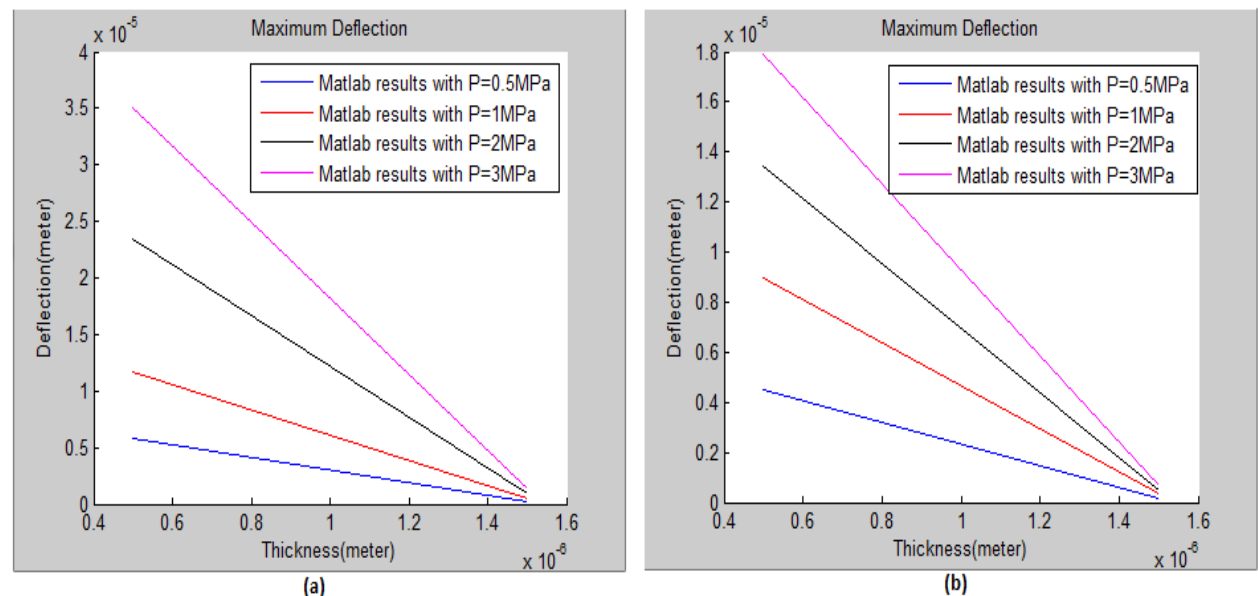

Fig.9: Plot of the deflection through different applied pressure with the range of diaphragm thickness (a) For circular shaped diaphragm, (b) For square shaped diaphragm. 


\section{2- Stress}

If applied pressure is increased, stress increases as shown in Fig.10 (a) circular diaphragm and Fig.10 (b) square diaphragm, which show how the stress for different applied pressure varying with diaphragm thickness. For different applied pressure, stress in square shaped diaphragm is much higher than in circular shaped diaphragm.

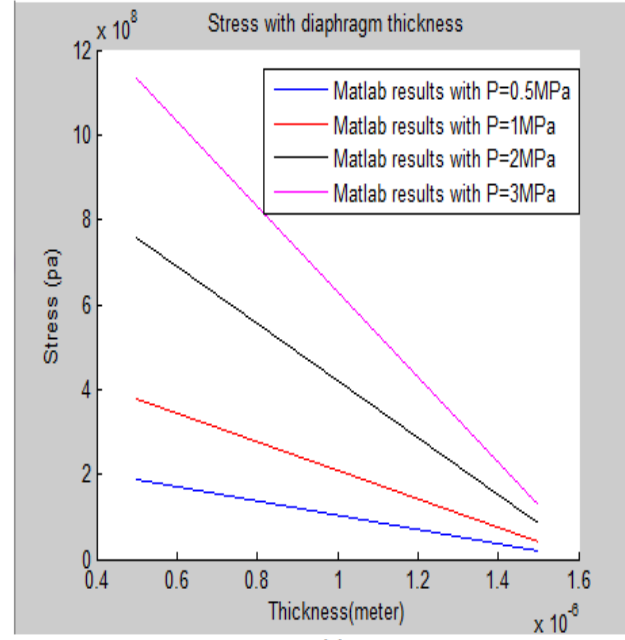

(a)

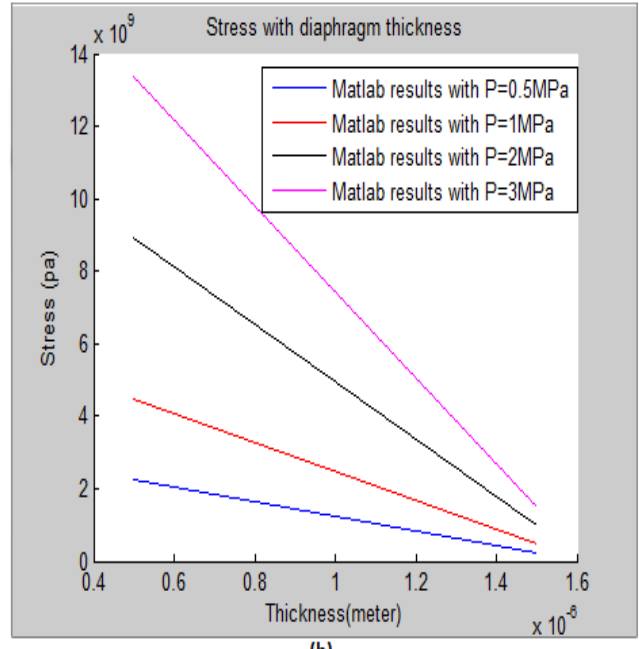

(b)

Fig.10: Plot of the stress through different applied pressure with the range of diaphragm thickness (a) For circular shaped diaphragm, (b) For square shaped diaphragm.

\section{3- Change in capacitance}

Change in capacitance is measured with respect to diaphragm thickness is shown in Fig.11 (a) circular diaphragm and Fig.11 (b) square diaphragm; it is observed that diaphragm thickness vs. change in capacitance is maximum for thin diaphragm. For different applied pressure, change in capacitance in circular shaped diaphragm is much higher than in square shaped diaphragm. 


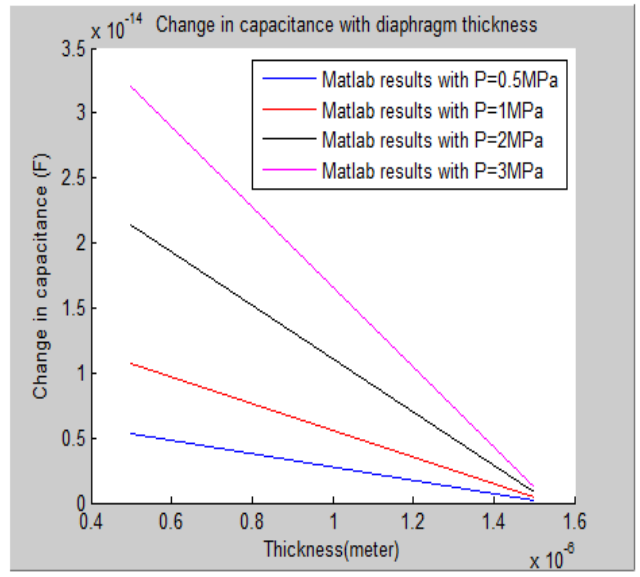

(a)

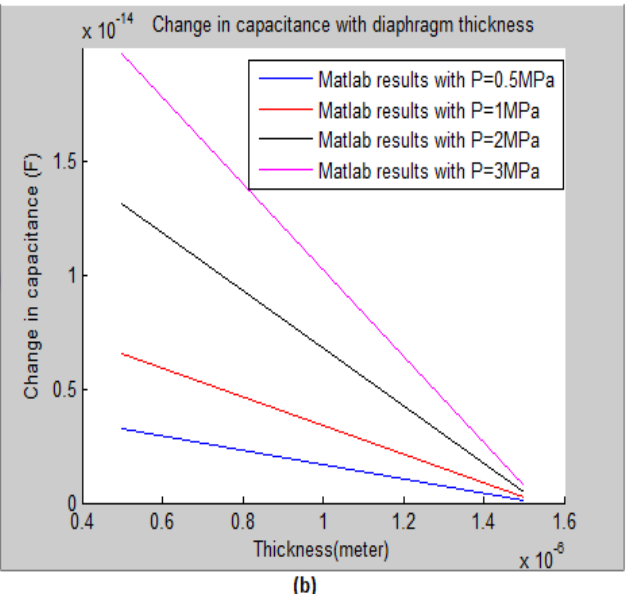

(b)

Fig.11: Plot of the change in capacitance through different diaphragm thickness with the range of applied pressure (a) For circular shaped diaphragm, (b) For square shaped diaphragm.

\section{4- Sensitivity}

If applied pressure is increased, sensitivity decreases. Diaphragm sensitivity is inversely proportional to applied pressure as shown in Fig.12 (a) circular diaphragm and Fig.12 (b) square diaphragm, which show how the sensitivity for different applied pressure varying with diaphragm thickness. For different applied pressure, sensitivity in circular shaped diaphragm is much higher than in square shaped diaphragm.

Table 3: Results obtained for both circular and square diaphragms at pressure $3 \mathrm{MPa}$

\begin{tabular}{|c|c|c|c|c|c|c|c|c|}
\hline \multirow{2}{*}{$\begin{array}{c}\text { Performance } \\
\text { of sensor }\end{array}$} & \multicolumn{4}{|c|}{ Circular diaphragm } & \multicolumn{4}{|c|}{ Square diaphragm } \\
\hline & $\mathrm{h}=0.5 \mu \mathrm{m}$ & $\mathrm{h}=1 \mu \mathrm{m}$ & $\mathrm{h}=1.5 \mu \mathrm{m}$ & $\mathrm{h}=2 \mu \mathrm{m}$ & $\mathrm{h}=0.5 \mu \mathrm{m}$ & $\mathrm{h}=1 \mu \mathrm{m}$ & $\mathrm{h}=1.5 \mu \mathrm{m}$ & $\mathrm{h}=2 \mu \mathrm{m}$ \\
\hline $\begin{array}{l}\text { Deflection } \\
(\mu \mathrm{m})\end{array}$ & 35 & 4.3 & 1.3 & 0.54 & 26 & 3.3 & 0.99 & 0.41 \\
\hline Stress (MPa) & 1130 & 283 & 125.97 & 70.85 & 13300 & 3330 & 1483.2 & 834.3 \\
\hline $\begin{array}{l}\text { Sensitivity } \\
(\mathbf{a F} / \mathbf{P a})\end{array}$ & $\begin{array}{r}10.68 \\
\times 10^{-21}\end{array}$ & $\begin{array}{l}1.335 \\
\times 10^{-21}\end{array}$ & $\begin{array}{c}0.39 \\
\times 10^{-21}\end{array}$ & $\begin{array}{l}0.1669 \\
\times 10^{-21}\end{array}$ & $\begin{array}{r}6.578 \\
\times 10^{-21}\end{array}$ & $\begin{array}{r}0.822 \\
\times 10^{-21}\end{array}$ & $\begin{array}{r}0.243 \\
\times 10^{-21}\end{array}$ & $\begin{array}{l}0.102 \\
\times 10^{-21}\end{array}$ \\
\hline
\end{tabular}




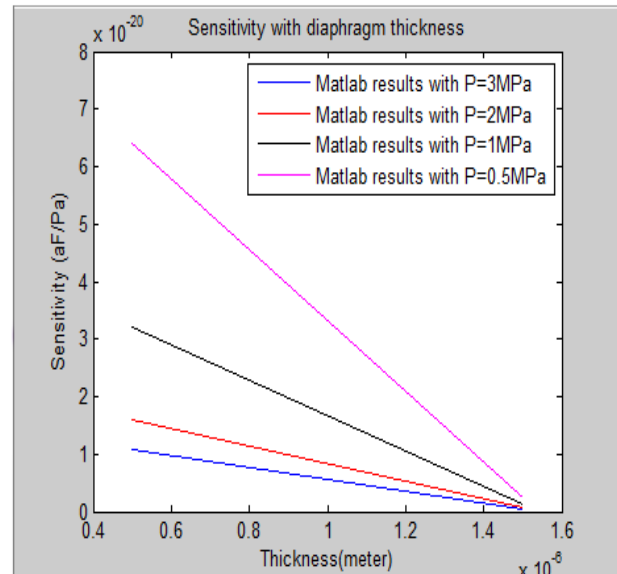

(a)

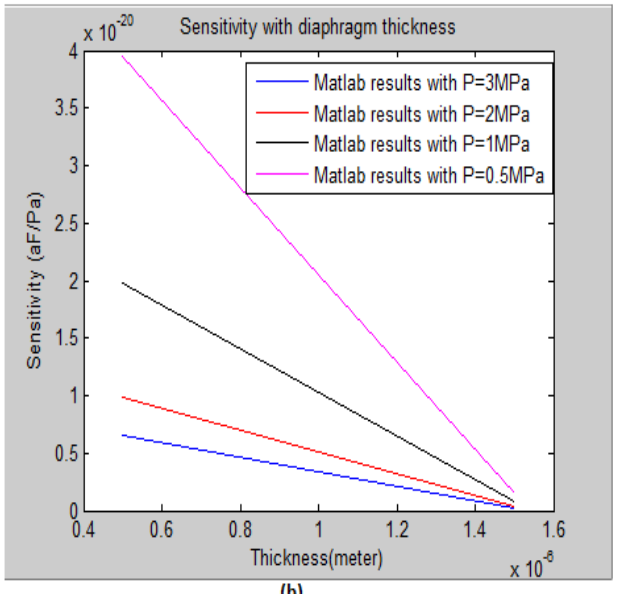

(b)

Fig.12: Plot of the sensitivity through different applied pressure with the range of diaphragm thickness (a) For circular shaped diaphragm, (b) For square shaped diaphragm

Table 4: Results obtained for both circular and square diaphragms at diaphragm thickness $0.5 \mu \mathrm{m}$

\begin{tabular}{|c|c|c|c|c|c|c|c|c|}
\hline \multirow{2}{*}{$\begin{array}{c}\text { Performan } \\
\text { ce of } \\
\text { sensor }\end{array}$} & \multicolumn{4}{|c|}{ Circular diaphragm } & \multicolumn{4}{c|}{ Square diaphragm } \\
\cline { 2 - 8 } & $\begin{array}{c}\mathbf{P}=\mathbf{0 . 5} \\
\mathbf{M P a}\end{array}$ & $\begin{array}{c}\mathbf{P}=\mathbf{1} \\
\mathbf{M P a}\end{array}$ & $\begin{array}{c}\mathbf{P}=\mathbf{2} \\
\mathbf{M P a}\end{array}$ & $\begin{array}{c}\mathbf{P}=\mathbf{3} \\
\mathbf{M P a}\end{array}$ & $\begin{array}{c}\mathbf{P}=\mathbf{0 . 5} \\
\mathbf{M P a}\end{array}$ & $\begin{array}{c}\mathbf{P}=\mathbf{1} \\
\mathbf{M P a}\end{array}$ & $\begin{array}{c}\mathbf{P}=\mathbf{2} \\
\mathbf{M P a}\end{array}$ & $\begin{array}{c}\mathbf{P}=\mathbf{3} \\
\mathbf{M P a}\end{array}$ \\
\hline $\begin{array}{c}\text { Deflection } \\
(\boldsymbol{\mu m})\end{array}$ & 5.8 & 11 & 23 & 35 & 4.4 & 8.9 & 13 & 17 \\
\hline $\begin{array}{c}\text { Stress } \\
(\mathbf{M P a})\end{array}$ & 188 & 377 & 755 & 1130 & 2220 & 4440 & 8890 & 13300 \\
\hline $\begin{array}{c}\text { Sensitivity } \\
(\mathbf{a F} / \mathbf{P a})\end{array}$ & 64 & 32 & 16 & 10.6 & 39 & 19 & 9.8 & 6.5 \\
$\times 10^{-21}$ & $\times 10^{-21}$ & $\times 10^{-21}$ & $\times 10^{-21}$ & $\times 10^{-21}$ & $\times 10^{-21}$ & $\times 10^{-21}$ & $\times 10^{-21}$ \\
\hline
\end{tabular}

\section{Conclusions}

In this paper, two different models of MEMS based capacitive pressure sensor are analyzed. One having circular shaped whereas other having square shaped diaphragm. The results obtained evaluating the performance of MEMS capacitive 
pressure sensor for both circular and square diaphragms in deflection, stress and sensitivity as shown in tables 3 and 4 .

Detailed simulation based analyses on the mechanical, electromechanical as well as polysilicon material was performed. From the results obtained, it is shown that the circular diaphragm has the lowest stress on its edges when applying the same pressure as on a square diaphragm, but the largest centre deflection can be seen in circular diaphragm and sensitivity of circular diaphragm is greater than sensitivity of square diaphragm. Besides, Matlab modeling was performed to simulate the mechanical characteristics of the diaphragm and the comparison to FEM (Finite Element Method) based Multiphysics simulation platform is presented. As analyzed from the mechanical analysis that designed model can withstand a high absolute pressure range extends to several of mega Pascals. This design technology allows for simple and inexpensive batch fabrication and integration of this type of sensors with dedicated signal detection circuits. Thus, the practical implementation of these designed sensors will cater wide range of applications over a varied field (biomedical, robotics etc).

\section{References}

[1] Y. Kanda, A graphical representation of the piezoresistance coefficients in silicon,IEEE Transactions on Electron Devices ED-29 (1982) 64-70

[2] J.-S. Park, Y.B. Gianchandani, A servo-controlled capacitive pressure sensor using a capped-cylinder structure microfabricated by a three-mask process, Journal of Microelectromechanical Systems 12 (2003) 209-220.

[3] K. Kasten, J. Amelung, W. Mokwa, CMOS-compatible capacitive high temperature pressure sensors, Sensors and Actuators 85 (2000) 147-152.

[4] C.Kolle,W. Scherr, D. Hammerschmidt, G. Pichler,M.Motz, B. Schaffer, B. Forster, U. Ausserlechner, Ultra low-power monolithically integrated capacitive pressure sensor for tirepressuremonitoring, in: Proceedings of IEEE Sensors, Vienna, Austria, 24-27 October 2004, 2004, pp. 244-247.

[5] M. Habibi, E. Lueder, T. Kallfass, D. Horst, A surface micromachined capacitive absolute pressure sensor array on a glass substrate, Sensors and Actuators A 46-47 (1995) 125-128.

[6] U. Paschen, M. Leineweber, J. Amelung, M. Schmidt, G. Zimmer, A novel tactile sensor system for heavy-load applications based on an integrated capacitive pressure sensor, Sensors and Actuators A 68 (1998) 294-298. 
[7] W.H.Ko,Q.Wang, Touchmode capacitive pressure sensor, Sensors andActuators 75 (1999) 242-251.

[8] P. Dimitropoulos, C. Kachris, D. Karampatzakis, G. Stamoulis, A new SOI monolithic capacitive sensor for absolute and differential pressure measurements, Sensors and Actuators A 123-124 (2005) 36-43.

[9] S.T. Moe, K. Schjølberg-Henriksen, D.T.Wand, E. Lund, J. Nysæther, L. Furuberg,M. Visser, T. Fallet, R.W. Bernstein, Capacitive differential pressure sensors for harsh environments, Sensors and Actuators A 83 (2000) 30-33.

[10] R. Puers, Capacitive sensors: when and howto use them, Sensors and Actuators A 37-38 (1993) 93-105.

[11] A.V. Chavan, K.D. Wise, Batch-processed vacuum-sealed capacitive pressure sensors, J. of Microelectromechanical Syst. 4 (10),580-588, 2001.

[12] P. S. Roy, M. Chattopadhyay, "A Simulation Based Geometrical Analysis of MEMS Capacitive Pressure Sensors for High Absolute Pressure Measurement", ISSN 2250-2459, IESA 2014.

[13] D. M. M Zeena," Design and Implementation of Piezo Resistive MEMS Pressure Sensor for Spiro Meter Application", International Journal of Innovative Research in Science, Engineering and Technology, Volume 3, Special Issue 3, March 2014.

[14] A.A. Barlian , W.-T. Park, J,R. Mallon, A.J.Rastegar, and B.L. Pruitt, “ Review: Semiconductor Piezoresistance for Microsystems," Proc. IEEE, vol.97, no.3, pp.513-552,2009.

[15] Chang ,S.-P., and Allen ,M.G.,2004,"Capacitive Pressure Sensors with Stainless Steel Diaphragm and Substrate ." J.Micromechan.Microeng., 14(4),pp.612-618.

[16] Sathyanarayanan,S.,Vimala Juliet, A.,2007, " Design of Wireless Pressure Sensor for Monitoring Intraocular Pressure" Proceedings of 2nd ISSS national conference on MEMS, Microsensors, Smart materials, Structures and Systems, C36,pp.28-29.

[17] Y. Zhang, S. Massoud-Ansari, G. Meng, W. Kim, and N. Najafi, "A UltraSensitive, High-Vacuum Absolute Capacitive Pressure Sensor," Technical Digest of the $14^{\text {th }}$ IEEE Int. Conf. on Micro Electro Mechanical Systems (MEMS 2001), pp. 166-169, Interlaken, Switzerland, Jan. 21-25, 2001.

[18] Y. Zhang and K. D. Wise, "A Barometric Pressure Sensor with Multiple Elements,” Digest IEEE Transducers '95 Stockholm, Sweden, June 1995.

[19] Y. Zhang and K. D. Wise, " An Ultra-Sensitive Capacitive Pressure Sensor with a Bossed Dielectric Diaphragms," Technical Digest of IEEE Solidstate Sensors and Actuators workshop, Hilton Head Island, June of 1994. 
[20] C. Hierold, B. Clasbrummel. "Low power integrated pressure sensor system for medical applications," Sensors and Actuators (Part A) Physical, no. 73,1999 , pp. $68-67$

[21] Bishnu P. Gogoi and David J. Monk, "Method of manufacturing a semiconductor component having a fixed electrode between two flexible diaphragms," U.S. Patent \#6,426,239 B1, issued July 30, 2002.

\section{ملخص البحث}

فى هذه الورقة البحثية نقدم تقييم للنظم الميكانيكية والكهربية الدقيقة الخاصة

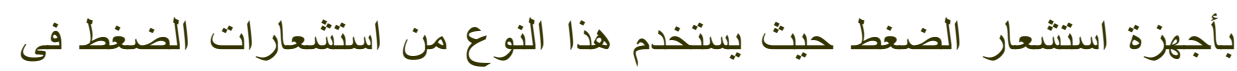
قياس معدل النبض. تم تحليل الاداء لنوعين من اجزةة استشعار الضغط بأنثكال

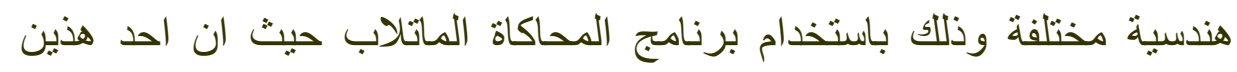
النوعين يأخذ شكل دائرى فى حين الاخر يأخد شكل مربع0 تم تقييم اداء النظم بـاء

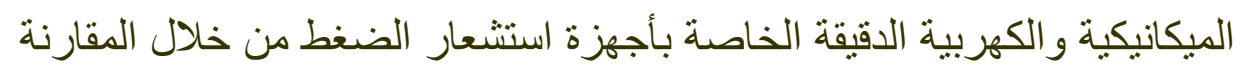

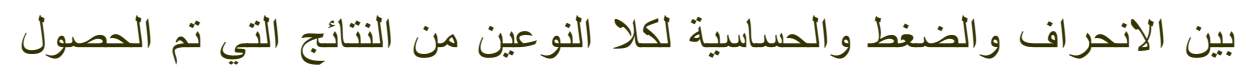

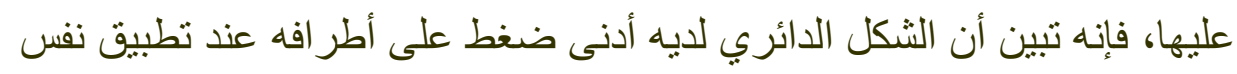

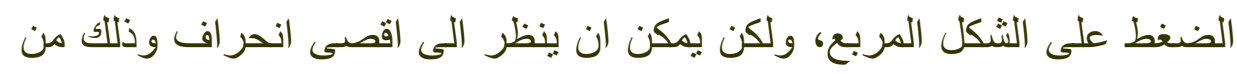

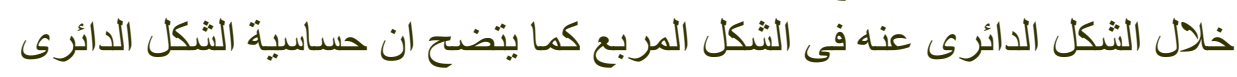

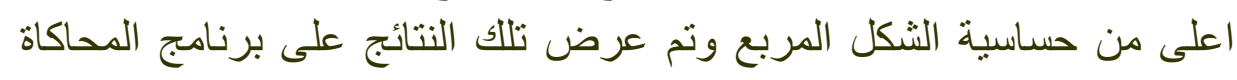
الماتلاب ونأكد من مطابقتها مع النتائج الموضحة وثل على برضئ نامج (FEM).

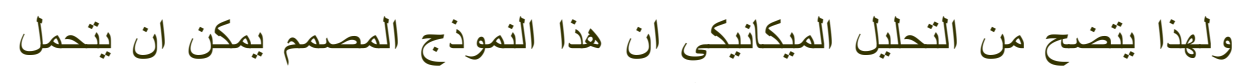
اقصى مدى من الضغط المطلق يصل الى (several of mega Pascals). هذا التصميم التكنولوجى يسمح بتصنيع ودمج هذه الانواع من اجهزة استشعار

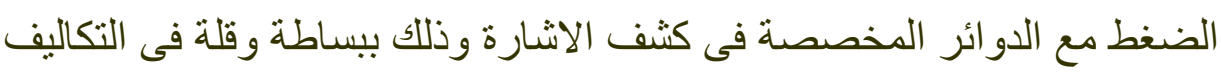

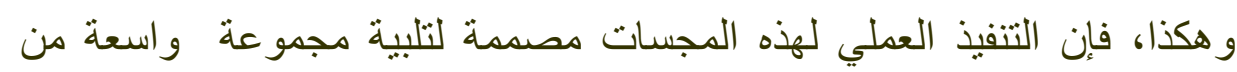

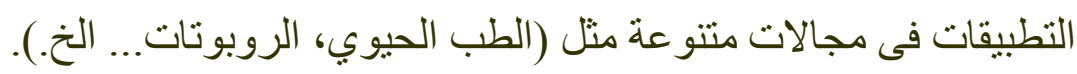

